\title{
High Resolution Gas Adsorption Study on Montmorillonite Clays from Côte d'Ivoire: Assessment of Surface Energetic Properties
}

\author{
E. B. Kpangni ${ }^{1}$, Y. J. Andji ${ }^{1}$, K. Adouby ${ }^{2 *}$, S. Oyetola ${ }^{1}$, J. Yvon ${ }^{3}$ \\ ${ }^{1}$ Laboratory of Inorganic Material Chemistry, University of Cocody, Abidjan, Côte d'Ivoire; ${ }^{2}$ Laboratory of Industrial Process, Synthesis, \\ Environment and New Energy, National Polytechnic Institute Felix Houphouët-Boigny, Yamoussoukro, Côte d'Ivoire; ${ }^{3}$ Laboratory \\ of Environment and Mineralurgy, National Polytechnic Institute of Loraine-Nancy, Nancy, France. \\ Email: *kadouby@yahoo.fr
}

Received October $2^{\text {nd }}, 2011$; revised December $12^{\text {th }}, 2011$; accepted December $30^{\text {th }}, 2011$

\begin{abstract}
The surface heterogeneity of two samples of montmorillonite clays from Katiola (Côte d'Ivoire), referenced $\mathrm{K}_{1}$ and $\mathrm{K}_{2}$, has been explored by low-pressure of argon and nitrogen adsorption at $77 \mathrm{~K}$. The adsorption isotherms of the studied samples have been modelled by the Derivative Isotherms Summation method (DIS method) in a satisfactory manner, with the help of local isotherms to argon and nitrogen. The use of the DIS method allowed us to quantify the basal and lateral surfaces, then to determine the total surface of studied materials. Beyond the quantitative aspect, the DIS method permitted us to determine the lamellarity index of the clay grains and to describe the two studied samples of a family of high energy site ( $-14 \mathrm{kT}$ to nitrogen), that shows a strong affinity for the polar adsorbates.
\end{abstract}

Keywords: Surface Heterogeneity; Montmorillonite; Clay; Adsorption Isotherm; DIS Method; Energetic Properties

\section{Introduction}

The strong increase of the population and the uncontrolled industrialization policy in Côte d'Ivoire are the results of a more and more increasing production of solid and liquid wastes [1]. The management of these wastes is generally restricted to a simple collection and a setting of illegal dumping without previous treatment [2].

The discharges, sum total of all types of waste, constitute polluted sites. Indeed, this mode of management of waste presents potential hazards of environmental pollution $[3,4]$. In order to limit the expansion of the pollution and to guarantee the protection of the environment, the creation of Technical Burying Centers (C.E.T. in French) is considered by using clay materials. Indeed, Côte d'Ivoire has a lot of clayey deposit that has been studied [5-7]. In a lot of processes that make with the clayey material, it is necessary to determine with precision the distribution of the different faces, to study in good conditions the mechanisms that have place and the properties that result. Therefore a better knowledge of surface properties of these clay minerals is necessary.

Currently the approaches based on gas adsorption appear as the most effective in the study of the heterogeneity of materials [8-11].

"Corresponding author.
The acquisition of precise isotherms from the very low pressures, coupled with the modelling of the derivative isotherms today, permits us to reach numerous informations on the superficial energizing properties of the solid. To this effect, the use of the DIS method permits the quantification of the basal and lateral surfaces, and therefore the determination of the total surface of the studied materials $[12,13]$.

The present study is concerned two montmorillonite clays from the deposit of Katiola (Côte d'Ivoire). It is a contribution to the literature on external properties of the argillaceous materials, which are likely to be employed like alternate materials in the technology of environmental protection [14-16].

\section{Experimental}

The montmorillonite clays (referenced to as $\mathrm{K}_{1}$ and $\mathrm{K}_{2}$ ) used in this study were collected from Katiola (in the center of Côte d'Ivoire). The mineralogical composition of these clays were reported to be $74.5 \%$ of montmorillonite, $7 \%$ of kaolinite and $5.4 \%$ of illite associated with inter-stratified clay (13.5\%) for $\mathrm{K}_{1}$ and $73.4 \%$ of montmorillonite $23.5 \%$ of kaolinite and $3.1 \%$ of illite for $\mathrm{K}_{2}$ [5].

To prevent the effect of exchangeable cations on the 
gas adsorption, the samples were purified and subsequently saturated with $\mathrm{Na}^{+}$cations by washing the clay fraction $(\phi<2 \mu \mathrm{m})$ repeatedly with concentred solution of $\mathrm{NaCl}$. Twenty grams portions of the clay were treated with $1 \mathrm{~mol} \cdot \mathrm{L}^{-1} \mathrm{NaCl}$ solution. The suspension was vigorously shaken at room temperature with magnetic agitation for $1 \mathrm{~h}$. Then, the cation-saturated montmorillonite was separated by centrifugation (30 $\mathrm{min}$ at 19,000 rpm) and decantation of the supernatant solutions [17]. This process was repeated three times. The cation-saturated montmorillonite was then washed three or four times with distilled water until the $\mathrm{AgNO}_{3}$ test for chloride became negative $[18,19]$.

The cation-saturated montmorillonite was subsequently dried during three to five days at $40^{\circ} \mathrm{C}$ and finally ground in an agate mortar. X-ray diffraction was achieved on the powder gotten with a Brucker's D8 diffractometer that uses Co-K monochromatic radiation $(\lambda=1.7889$ $\AA$ ). Adsorption isotherms of nitrogen and argon, studied by a quasi-equilibrium gas adsorption procedure [20,21], were achieved after out gassing at $110^{\circ} \mathrm{C}$ during 24 hours. The pressure measurement is achieved with two absolute $0 \mathrm{~Pa}-0.1 \mathrm{~Pa}$ and $0 \mathrm{~Pa}-10 \mathrm{~Pa}$ sensors Edwards, with an automatic adsorbometer equipped with a turbo molecular pump, in order to ensure a dynamic vacuum up to $10^{-8} \mathrm{~Pa}$. The measurements of the saturation pressure of nitrogen and argon at $77 \mathrm{~K}$ are done with an independent system equipped with a $0 \mathrm{~Pa}-10 \mathrm{~Pa}$ sensor Edward.

This method permits one to acquire many experimental data. Then, it is possible to calculate an experimental derivative of the isotherm with respect to logarithm of the relative pressure. Such curves display peaks and valleys that can be modelled with a restricted number of local isotherms by using the Derivative Isotherms Summation (DIS) method $[12,13]$.

\section{Result and Discussion}

\subsection{X-Ray Diffraction}

The X-ray diffraction patterns obtained from Na-saturated clays are shown in Figure 1. The results indicate a centred major peak of about $12.2 \AA$, corresponding to the basal spacing $\mathrm{d}(001)$. This position of observed refection (001), translates a basal distance corresponding to the state hydrated means to a layer of water of exchangeable sodium cation. The peak towards 4.521 corresponds to an (hh0) reflexion. The other peaks 3.107 and $2.539 \AA$ are harmonic with the main stripe of the Na-saturated montmorillonite.

The X-ray diffraction patterns of $\mathrm{K}_{2}$ exhibits a peak at $7.3 \AA$, which is a harmonic to those at $3.542 \AA$ that translates a trace of kaolinite. Purification of $\mathrm{K}_{2}$ sample was therefore not complete.

\subsection{Gas Adsorption}

\subsubsection{Derivative Isotherms of Argon Adsorption}

The experimental derivative isotherms of argon adsorption on $\mathrm{K}_{1}$ and $\mathrm{K}_{2}$ are given respectively in Figures 2 and 3. The derivative isotherms were modelled in a satisfactory

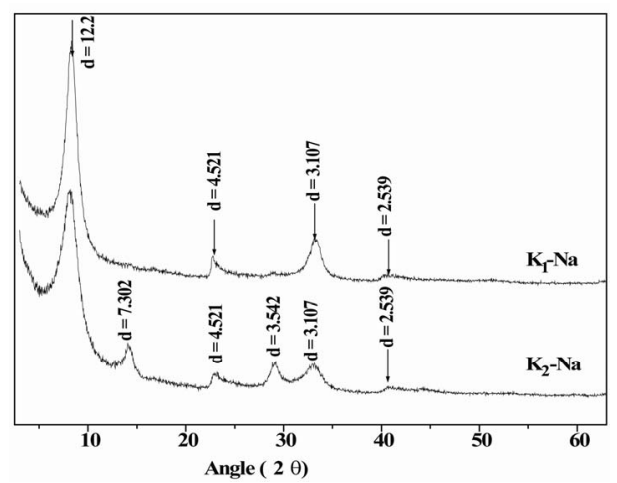

Figure 1. Comparison of $\mathrm{X}$-ray diffraction patterns of cation-saturated clays $\left(\mathrm{K}_{1}-\mathrm{Na}\right.$ and $\left.\mathrm{K}_{2}-\mathrm{Na}\right)$.

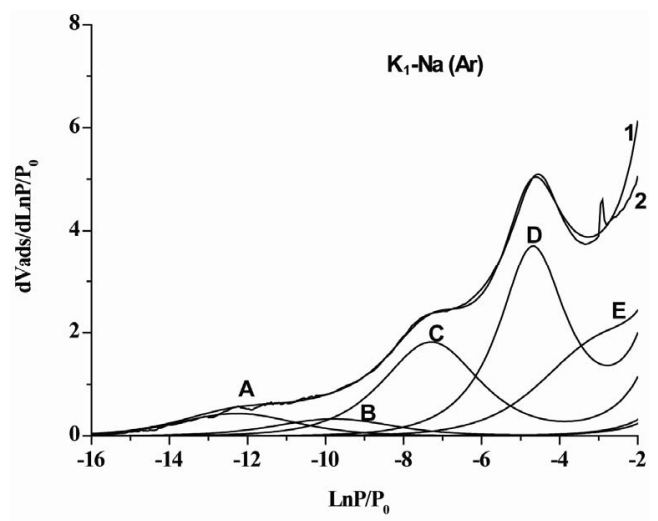

Figure 2. Result of the decomposition by the DIS method of the derivative adsorption isotherm of argon on $K_{1}$ saturated by sodium. Experimental data (1= dark yellow), calculated line $(2$ red) and $(A, B, C, D, E)$ the different domains.

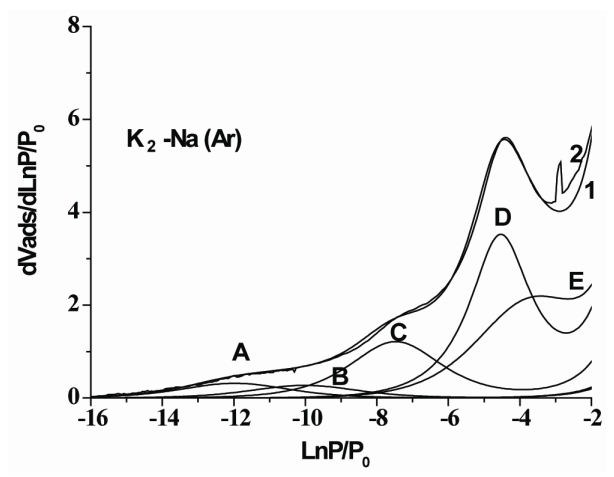

Figure 3. Result of the decomposition by the DIS method of the derivative adsorption isotherm of argon on $K_{2}$ exchanged by sodium. Experimental data 1; calculated line 2 and (A, $\mathrm{B}, \mathrm{C}, \mathrm{D}, \mathrm{E})$ the different domains. 
manner by using five local isotherms, following the BET model.

For the two samples, the obtained derivative isotherms present the same shape (Figures $\mathbf{2}$ and $\mathbf{3}$ ), as it is generally the case for the phyllosilicates. Tables 1 and 2 give the parameters collected by modelling the adsorption isotherms of $\mathrm{K}_{1}$ and $\mathrm{K}_{2}$ respectively. By analogy with data in the literature the local isotherms of stronger energy $\left(\ln \mathrm{P} / \mathrm{P}_{0}=-7.3\right.$ to -12.3$)$ observed can be assigned to the adsorption on the edge surfaces of the clayey particles $[12,21,22]$. In the same way, the isotherms of weaker energies (toward $\ln \mathrm{P} / \mathrm{P}_{0}=-3$ to -4.7 ), are assigned to the adsorption on the basal surfaces.

\subsubsection{Derivative Isotherms of Nitrogen Adsorption}

The experimental isotherms of nitrogen adsorption on $\mathrm{K}_{1}$ and $\mathrm{K}_{2}$ were plotted in Figures $\mathbf{4}$ and $\mathbf{5}$ respectively. As previously, the derivative isotherms were modelled in a satisfactory manner by using four and five local isotherms following the BET model for $\mathrm{K}_{1}$ and for $\mathrm{K}_{2}$ respectively. Here, the obtained derivative isotherms present small different shapes for $K_{1}$ and $K_{2}$ (Figures 4 and 5).

Table 1. Deducted values of modelling the adsorption isotherm of argon at $77 \mathrm{~K}$ on $\mathrm{K}_{1}-\mathrm{Na}$.

\begin{tabular}{|c|c|c|c|c|c|c|}
\hline Domains & $\mathrm{LnP} / \mathrm{P}_{0}$ & $\mathrm{LnC}$ & $\mathrm{w} / \mathrm{kt}$ & $\mathrm{V}_{\text {ads }} \mathrm{cm}^{3} / \mathrm{g}$ & $\mathrm{Ss} \mathrm{m}^{2} / \mathrm{g}$ & \\
\hline A & -12.3 & 213182.1 & 0 & 1.7 & 6.3 & Total surface $91.9 \mathrm{~m}^{2} / \mathrm{g}$ \\
\hline B & -9.8 & 17684.6 & 0 & 1.3 & 4.8 & Basal surface $(D+E): 57.8 \mathrm{~m}^{2} / \mathrm{g}$ \\
\hline $\mathrm{C}$ & -7.3 & 1091.2 & 0.6 & 6.2 & 23.0 & Lateral surface $(A+B+C): 34.1 \mathrm{~m}^{2} / \mathrm{g}$ \\
\hline $\mathrm{D}$ & -4.7 & 54.3 & 1.4 & 9.2 & 34.1 & \\
\hline $\mathrm{E}$ & -2.7 & 21.0 & 0 & 6.4 & 23.7 & \\
\hline
\end{tabular}

Table 2. Deducted values of modelling the adsorption isotherm of argon at $77 \mathrm{~K}$ on $\mathrm{K}_{2}-\mathrm{Na}$.

\begin{tabular}{ccccccc}
\hline Domains & $\mathrm{LnP} / \mathrm{P}_{0}$ & $\mathrm{LnC}$ & $\mathrm{w} / \mathrm{kt}$ & $\mathrm{V}_{\text {ads }}\left(\mathrm{cm}^{3} / \mathrm{g}\right)$ & $\mathrm{Ss}\left(\mathrm{m}^{2} / \mathrm{g}\right)$ & \\
\cline { 1 - 5 } $\mathrm{A}$ & -12.0 & 158126.5 & 0 & 1.3 & 4.8 & Total surface $85.7 \mathrm{~m}^{2} / \mathrm{g}$ \\
$\mathrm{B}$ & -10.0 & 22482.8 & 0 & 1.1 & 4.1 & Basal surface $(\mathrm{D}+\mathrm{E}): 61.2 \mathrm{~m} / \mathrm{g}$ \\
$\mathrm{C}$ & -7.5 & 1373.4 & 0.5 & 4.2 & 15.6 & Lateral surface $(\mathrm{A}+\mathrm{B}+\mathrm{C}): 24.5 \mathrm{~m}^{2} / \mathrm{g}$ \\
$\mathrm{D}$ & -4.5 & 46.9 & 1.4 & 8.7 & 32.3 & \\
$\mathrm{E}$ & -3.4 & 42.6 & 0 & 7.8 & 28.9 \\
\hline
\end{tabular}

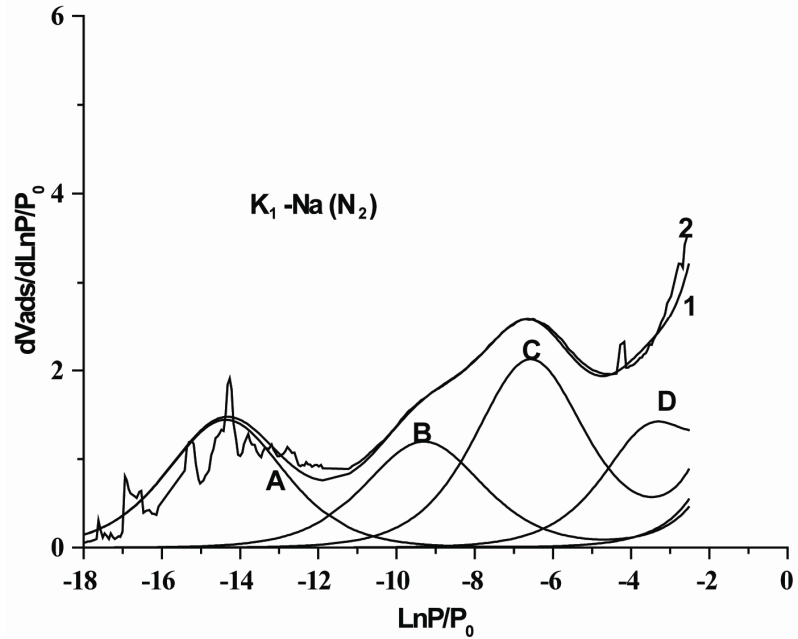

Figure 4. Result of the decomposition by the DIS method of the derivative adsorption isotherm of nitrogen on the $K_{1}$ saturated by sodium. Experimental data 1; calculated line 2 and $(A, B, C, D, E)$ the different domains.

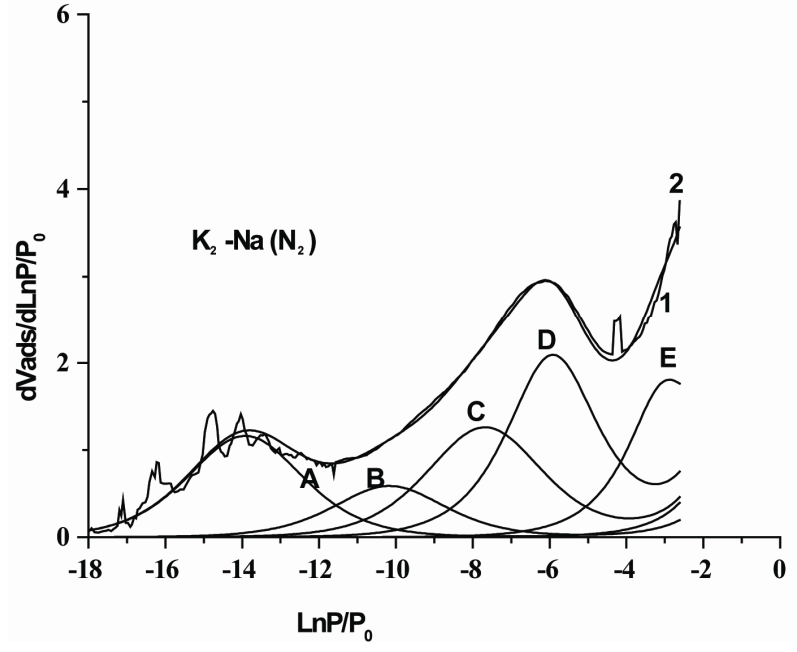

Figure 5. Result of the decomposition by the DIS method of the derivative adsorption isotherm of nitrogen on the $K_{2}$ exchanged by sodium. Experimental data 1; calculated line 2 and $(A, B, C, D, E)$ the different domains. 
Four and five domains have been classified through decreasing energy for $K_{1}$ and $K_{2}$ respectively. The parameters collected by nitrogen adsorption are listed in Tables 3 and 4.

Specifically for nitrogen, one can note that the position of the maximum of the peaks observed is baffled toward the strong energies, or even to the very strong energies (case of the A domain in Table 3).

This energy adsorption differences between argon and nitrogen can be attributable to the difference between the saturation pressures of these two gases, and probably to specific interactions of nitrogen with the solid surface [23].

Here again, in agreement with data found in the literature, the peaks with weak energy $(\mathrm{C}$ and $\mathrm{D}$ domains for $\mathrm{K}_{1}$ or $\mathrm{D}$ and $\mathrm{E}$ domains for $\mathrm{K}_{2}$ ) can be attributable to the adsorption on the basal faces. The other peaks of strong energies are assigned to the adsorption on the lateral surfaces even though; some cautions should be observed, because the affectation of the higher energy peak is not always obvious with nitrogen. It could correspond to particular sites of basal faces (shortcoming of surface), sites of lateral faces, or to micropores [21].

The sites of strong energy present on the surface of the solid studied, are observed with argon equally, but seem more accessible to nitrogen, in relation to the adsorbed volumes (Figures 3 and 4). The sites that have a structural origin are often made of groups $\mathrm{SiOH}$ and/or $\mathrm{AlOH}$, which are sensitive to amphoteric dissociation [24]. They can influence the adsorption of micro-pollutants or can be the seat of catalytic reactions, in a non-negligible manner.

The total specific surface of all samples (DIS surfaces), argon and nitrogen, has been calculated while adding the specific surface relative to the set of the domains (Figures 1 to 4). The specific surfaces values deducted from $\mathrm{K}_{1}$ and $\mathrm{K}_{2}$ are recapitulated in Table 5. Those observed in nitrogen are more than the DIS argon surfaces. This difference is explained from the assumption that nitrogen is able to probe "inaccessible" sites to argon $[25,26]$.

Table 3. Deducted values of modelling the adsorption isotherm of nitrogen at $77 \mathrm{~K} \mathrm{on} \mathrm{K}_{1}-\mathrm{Na}$.

\begin{tabular}{|c|c|c|c|c|c|c|}
\hline Domains & $\mathrm{LnP} / \mathrm{P}_{0}$ & $\mathrm{LnC}$ & $\mathrm{w} / \mathrm{kt}$ & $\mathrm{V}_{\text {ads }} \mathrm{cm}^{3} / \mathrm{g}$ & $\mathrm{Ss} \mathrm{m}^{2} / \mathrm{g}$ & \\
\hline A & -14.4 & 1732976 & 0 & 5.8 & 25.3 & Total surface $100 \mathrm{~m}^{2} / \mathrm{g}$ \\
\hline B & -9.3 & 10946.3 & 0 & 4.8 & 21 & Basal surface $53.7 \mathrm{~m}^{2} / \mathrm{g}$ \\
\hline $\mathrm{C}$ & -6.5 & 652.0 & 0.2 & 8.0 & 34.9 & Lateral surface $46.3 \mathrm{~m}^{2} / \mathrm{g}$ \\
\hline $\mathrm{D}$ & -3.3 & 26.6 & 0.5 & 4.3 & 18.8 & \\
\hline
\end{tabular}

Table 4. Deducted values of modelling the adsorption isotherm of nitrogen at $77 \mathrm{~K}$ on $\mathrm{K}_{2}-\mathrm{Na}$.

\begin{tabular}{|c|c|c|c|c|c|c|}
\hline Domains & $\mathrm{LnP} / \mathrm{P}_{0}$ & Ln C & $\mathrm{w} / \mathrm{kt}$ & $\mathrm{V}_{\text {ads }} \mathrm{cm}^{3} / \mathrm{g}$ & $\mathrm{Ss}^{2} / \mathrm{g}$ & \multirow{6}{*}{$\begin{array}{c}\text { Total surface } 100.4 \mathrm{~m}^{2} / \mathrm{g} \\
\text { Basal surface } 48.5 \mathrm{~m}^{2} / \mathrm{g} \\
\text { Lateral surface } 51.9 \mathrm{~m}^{2} / \mathrm{g}\end{array}$} \\
\hline A & -13.9 & 1113842 & 0 & 4.6 & 20.1 & \\
\hline B & -10.2 & 24836.4 & 0.1 & 2.3 & 10.0 & \\
\hline $\mathrm{C}$ & -7.7 & 2173.8 & 0 & 5.0 & 21.8 & \\
\hline D & -5.9 & 263.8 & 0.7 & 6.8 & 29.7 & \\
\hline E & -2.9 & 12.5 & 1.1 & 4.3 & 18.8 & \\
\hline
\end{tabular}

Table 5. Summary of specific surfaces values deducted for $K_{1}$ and $K_{2}$ (DIS surface: $\mathbf{m}^{2} / g$ ).

\begin{tabular}{ccccccc}
\hline & \multicolumn{3}{c}{ Adsorbate } \\
\hline \multirow{2}{*}{ Samples } & \multicolumn{3}{c}{ Argon } & & \multicolumn{2}{c}{ Nitrogen } \\
\hline & Basal surface & Lateral surface & Total surface & Basal surface & Lateral surface & Total surface \\
\hline $\mathbf{K}_{\mathbf{1}}$ & 57.8 & 34.1 & $\mathbf{9 1 . 9}$ & 53.7 & 46.3 & 100.0 \\
$\mathbf{K}_{2}$ & 61.2 & 24.5 & $\mathbf{8 5 . 7}$ & 70.3 & 30.1 & 100.4 \\
\hline
\end{tabular}


The size of the nitrogen molecule is appreciably identical to the one of argon. Then, the supplementary sites probed by nitrogen, can be assigned to specific interactions between nitrogen and the superficial polar sites.

This difference supposes the presence of probable polar sites on the surface of the solid, which constitutes important information for the possible uses of these materials. Indeed, according to Legens [27] and Chamerois et al. [28], knowledge of the polar or no polar character of the solid surface permits one to deduce the importance of the exchanges mineral-solution, by electrostatic origin and equally to deduce the retention of organic pollutants capable of being set by hydrogen links, notably non ionic tensioactives, often present in industrial sewages.

Lamellar indication of the samples (IL = basal surface/ total surface) has been calculated from the isotherms of argon adsorption. The determination of the middle shape of the grains is very important for the use of the solid mineral in many domains. Indeed, the mechanisms and the kinetics of sorption, dissolution/precipitation depend on the shape of the particles. In the present case, the values of IL calculated are of $62 \%$ for $\mathrm{K}_{1}$ and $72 \%$ for $\mathrm{K}_{2}$. These indications suppose for the studied samples, a relative sharpness of the solid grains.

\section{Conclusions}

At the end of this work, two main conclusions can be drawn.

First, the use of Derivative Isotherms Summation (DIS) method has permitted us to describe and quantify the two bentonite clays (referenced to as $\mathrm{K}_{1}$ and $\mathrm{K}_{2}$ ) from Katiola in Côte d'Ivoire, total specific surface are for $\mathrm{K}_{1}$ : 91.9 $\mathrm{m}^{2} / \mathrm{g}$ to argon and $100 \mathrm{~m}^{2} / \mathrm{g}$ and for $\mathrm{K}_{2}: 85.7 \mathrm{~m}^{2} / \mathrm{g}$ to argon and $100.4 \mathrm{~m}^{2} / \mathrm{g}$ to nitrogen.

Second, Beyond the quantitative aspect, the DIS method has permitted us to describe the two samples, a family of high energy site ( $-14 \mathrm{kT}$ to nitrogen), that shows a strong affinity for the polar adsorbates. In the same way, Lamellar Indication of the samples (IL) calculated are of $62 \%$ for $\mathrm{K}_{1}$ and $72 \%$ for $\mathrm{K}_{2}$. These indications supposed for the studied samples, a relative sharpness of the solid grains, which shows important property of adsorption in various domains, notably in environment sciences.

\section{Acknowledgements}

This study was done in the Laboratory Environment and Mineralurgy (LEM) of Nancy. We are grateful to the staff members of the LEM for their invaluable contribution to this work.

We take this opportunity to thank the French department of foreign affairs for financial support to this work.

\section{REFERENCES}

[1] K. Adouby, L. C. K. Akissi, E. N. Wandan and B. Yao, "Removal of Heavy Metal Ions $\left(\mathrm{Pb}^{2+}, \mathrm{Cu}^{2+}\right)$ in Aqueous Solutions by Pterygota macrocarpa Sawdust," Journal of Applied Sciences, Vol. 7, No. 14, 2007, pp. 1864-1872. doi:10.3923/jas.2007.1864.1872

[2] A. Y. Yobouet, K. Adouby, A. Trokourey and B. Yao, "Cadmium, Copper, Lead and Zinc Speciation in Contaminated Soils," International Journal of Engineering Science and Technology, Vol. 2, No. 5, 2010, pp. 802812.

[3] R. Mejbri, G. Matejka, P. Lafrance and M. Mazet, "Fractionation and Characterization of the Organic Matter in Sanitary Landfill Leachates," Journal of Water Science, Vol. 8, No. 2, 1995, pp. 217-236.

[4] M. El-Fadel, A. N. Findikakis and J. O. Leckie, "Environmental Impacts of Solid Waste Landfilling," Journal of Environmental Management, Vol. 50, No. 1, 1997, pp. 1-25. doi:10.1006/jema.1995.0131

[5] E. B. Kpangni, Y. Y. J. Andji, K. Adouby, S. Oyetola, G. Kra and J. Yvon, "Mineralogy of Clay Raw Materials from Côte d'Ivoire: Case of the Deposit from Katiola," Journal of Applied Sciences, Vol. 8, No. 5, 2008, pp. 871-875. doi:10.3923/jas.2008.871.875

[6] J. Y. Y. Andji, A. A. Toure, G. Kra and J. Yvon, "Variability of Clays from Gounioube Deposit (Ivory Coast)," Journal of Applied Sciences, Vol. 9, No. 7, 2009, pp. 1238-1247. doi:10.3923/jas.2009.1238.1247

[7] K. L. Konan, J. Soro, J. Y. Y. Andji, S. Oyetola and G. $\mathrm{Kra}$, "Comparative Study of Dehydroxylation/Amorphization in Two Kaolins with Different Crystallinity," Journal de la Société Ouest-Africaine de Chimie, 2010, pp. 29-39.

[8] L. Michot, M. François and J. M. Cases, "Surface Heterogeneity Studied by a Quasi-Equilibrium Gas Adsorption Procedure," Langmuir, Vol. 6, No. 3, 1990, pp. 677-681. doi:10.1021/la00093a025

[9] K. L. Nagy, R. T. Cygan, J. M. Hanchar and N. C. Sturchio, "Gibbsite Growth Kinetics on Gibbsite, Kaolinite, and Muscovite Substrates: Atomic Force Microscopy Evidence for Epitaxy and an Assessment of Reactive Surface Area," Geochimica et Cosmochimica Acta, Vol. 63, No. 16, 1999, pp. 2337-2351.

doi:10.1016/S0016-7037(99)00118-0

[10] M. Chamerois, "Interactions between Mineral Surfaces and Functionalized Trisiloxanes: Application to the Waterproofing," Ph.D. Dissertation, National Polytechnic Institute of Lorraine Nancy, France, 2000.

[11] A. Cadene, S. Durand-Vidal, P. Turq and J. Brendle, "Study of Individual Na-Montmorillonite Particles Size, Morphology and Apparent Charge," Journal of Colloid and Interface Science, Vol. 285, No. 2, 2005, pp. 719-730. doi:10.1016/j.jcis.2004.12.016

[12] F. Villiéras, J. M. Cases, M. François, L. Michot and F. Thomas, "Texture and Surface Energetic Heterogeneity of Solids from Modeling of Low Pressure Gas Adsorption Isotherms," Langmuir, Vol. 8, No. 7, 1992, pp. 11891195. 
[13] F. Villiéras, L. Michot, J. M. Cases, F. Bardot, M. François and W. Rudzinski, "An Improved Derivative Isotherm Summation Method to Study Surface Heterogeneity of Clay Mineral," Langmuir, Vol. 13, No. 5, 1997, pp. 1104-1117. doi:10.1021/la9510083

[14] J. M. Cases, "Natural Minerals and Divided Solids: Methodology for Understanding Surface Phenomena Related to Industrial Uses and Environmental Problems," Comptes Rendus Geoscience, Vol. 334, No. 9, 2002, pp. 585-596. doi:10.1016/S1631-0713(02)01797-2

[15] E. Erdem, N. Karapinar and R. Donat, "The Removal of Heavy Metal Cations by Natural Zeolites," Journal of Colloid and Interface Science, Vol. 280, No. 2, 2004, pp. 309-341. doi:10.1016/j.jcis.2004.08.028

[16] Y. Luna, E. Otal, L. F. Viches, J. Vale, X. Querol and C. F. Pereira, "Use of Zeolitised Coal Fly Ash for Landfill Leachate Treatment: A Pilot Plant Study," Waste Management, Vol. 27, No. 12, 2007, pp. 1877-1883. doi:10.1016/j.wasman.2006.10.016

[17] G. H. Montes, J. Duplay, L. Martinez, Y. Geraud and B. Rousset-Tournier, "Influence of Interlayer Cations on the Water Sorption and Swelling-Shrinkage of MX80 Bentonite," Applied Clay Science, Vol. 23, No. 5, 2003, pp. 309-321. doi:10.1016/S0169-1317(03)00130-3

[18] G. Rytwo, "Exchange Reactions in the Ca-Mg-Na-Montmorillonite System," Clays and Clay Minerals, Vol. 44, No. 2, 1996, pp. 276-285. doi:10.1346/CCMN.1996.0440212

[19] S. Y. Lee and S. J. Kim, "Delamination Behaviour of Silicate Layer by Adsorption of Cationic Surfactants," Journal of Colloid and Interface Science, Vol. 248, No. 2, 2002, pp. 231-238. doi:10.1006/jcis.2002.8222

[20] J. F. Delon and J. M. Slot, "The Measure of Adsorbents Porosity to Channels of Diameter Constant from Gas Adsorption Isotherms," Journal de Chimie Physique, Vol. 4, 1970, pp. 662-666.

[21] L. Michot, F. Villiéras, M. François, J. Yvon, R. Le Dred and J. M. Cases, "The Structural Microscopic Hydrophobicity of Talc," Langmuir, Vol. 10, No. 10, 1994, pp. 3765-3773. doi:10.1021/la00022a061

[22] J. M. Cases and F. Villiéras, "Thermodynamic Model of Ionic and Non Ionic Surfactant Adsorption-Abstraction on Heterogenous Surfaces," Langmuir, Vol. 8, No. 5, 1992, pp. 1252-1264. doi:10.1021/la00041a005

[23] F. Villiéras, L. J. Michot, E. Bernardy, M. Chamerois, C. Legens, G. Gérard and J. M. Cases, “Assessment of Surface Heterogeneity of Calcite and Apatite: From High Resolution Gas Adsorption to Solid-Liquid Interface," Colloids and Surfaces A, Vol. 146, No. 1, 1999, pp. 163174. doi:10.1016/S0927-7757(98)00810-3

[24] F. Villiéras, L. M. Michot, F. Bardot, M. Chamerois, C. Eypert-Blaison, M. François, G. Gérard and J. M. Cases, "Analysis of Surface Heterogeneity of Minerals," Comptes Rendus Geoscience, Vol. 334, No. 9, 2002, pp. 596-609. doi:10.1016/S1631-0713(02)01799-6

[25] F. Bardot, "Clay Minerals and Their Surface Heterogeneity: Influence of the Nature of Compensators Cations of Illite on the Mechanisms of Gas Adsorption," Ph.D. Dissertation, National Polytechnic Institute of Lorraine Nancy, France, 1998.

[26] F. Bardot, F. Villiéras, L. Michot, M. François, G. Gerard and J. M. Cases, "High Resolution Gas Adsorption Study on Illites Permutted with Various Cations: Assessment of Surface Energetic Properties," Journal of Dispersion Science and Technology, Vol. 19, No. 6, 1998, pp. 739759. doi:10.1080/01932699808913212

[27] C. Legens, "Study of the Mechanism of Benzoic Acid Adsorption on Calcite. Incidence on Absorptivity," Ph.D. Dissertation, University of Paris, Paris, 1997.

[28] M. Chamerois, M. François, F. Villiéras and J. Yvon, "Modification of Calcium Carbonate Surface Properties: Macroscopic and Microscopic Investigations," Journal of Adhesion Science and Technology, Vol. 13, 1999, pp. 1481-1493. 